\section{$\underset{\substack{\text { hommes } \\ \text { \& migrations }}}{ }$}

\section{Hommes \& migrations}

Revue française de référence sur les dynamiques

migratoires

1332 | 2021

Ce qui s'oublie et ce qui reste

\title{
Yves Charles Zarka (dir.), La France en récits
}

Paris, PUF, 2020, 870 p., $35 €$.

\section{Mustapha Harzoune}

\section{Q OpenEdition \\ 1 Journals}

\section{Édition électronique}

URL : https://journals.openedition.org/hommesmigrations/12463

DOI : 10.4000/hommesmigrations. 12463

ISSN : 2262-3353

\section{Éditeur}

Musée national de l'histoire de l'immigration

\section{Édition imprimée}

Date de publication : 1 janvier 2021

Pagination : 265-266

ISBN : 978-2-919040-54-4

ISSN : $1142-852 X$

Référence électronique

Mustapha Harzoune, "Yves Charles Zarka (dir.), La France en récits », Hommes \& migrations [En ligne],

1332 | 2021, mis en ligne le 01 janvier 2021, consulté le 26 juillet 2021. URL : http://

journals.openedition.org/hommesmigrations/12463; DOI : https://doi.org/10.4000/

hommesmigrations. 12463 


\section{La France en récits}

Yves Charles Zarka (dir.), Paris, PUF, 2020, 870 p., $35 €$.

«Au lieu de poser d'emblée la question du récit national qui fait l'objet d'affrontements

idéologiques, La France en récits 


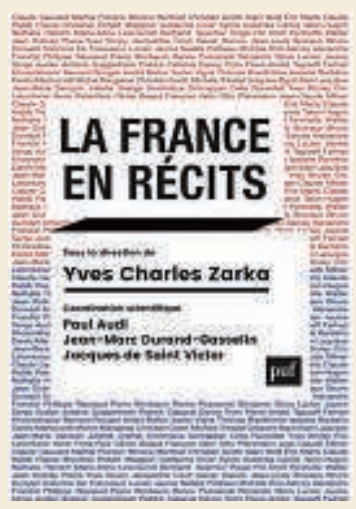

examine la manière dont les récits qui font la France se composent, se superposent, mais aussi s'opposent et s'affrontent. Au-delà de la diversité des lieux de mémoire, c'est à travers l'analyse de ces récits que l'on comprend comment se forge et se transforme l'identité de la France, à la fois une et divisée. "À la lecture de ce pavé dense et fertile, appelé à faire référence, la France pourrait se présenter comme une réponse à des équations à plusieurs inconnues et aux variables constantes et/ou mobiles. Elle pourrait aussi relever d'une géométrie de l'espace formé de cercles concentriques et centrifuges, configurés et reconfigurés à l'envie par l'Histoire et les Hommes, provoquant éloignements et rapprochements, tensions et relâchements, luttes et ententes, transformations et mutations, inclusions et exclusions, apparitions et disparitions, etc. Partant, UN récit ne suffirait pas à traduire le pays, comme UN moment à en faire l'histoire. Plus de soixante entrées, sans compter les introductions et conclusions de chapitres, et 62 auteurs, philosophes, sociologues, géographes, anthropologues... ne sont alors pas de trop pour appréhender ce qui est appelé ici " l'identité » de la France, en saisir les nombreuses facettes depuis ses permanences, elles-mêmes évolutives, ses fluctuations, contradictions, syncrétismes...

Si Michèle Tribalat ou Farhad Khosrokhavar remettent le couvert sur l'immigration ou sur les
« musulmans » et les «Arabes », si Pascal Bruckner sert un plat idéologique et sans densité, l'enthousiasme et l'intérêt gagnent le lecteur à la lecture des contributions. Mais le miel de cet ouvrage collectif n'est pas dans une sorte de comptabilité en partie double qui irait, in fine, à contrecourant de ce projet gigantesque : exposer, au sens propre, quasi muséal, une partie, une partie seulement, des multiples récits qui disent - font? - la France et ses habitants. Car on pourrait encore en ajouter, des thèmes, des moments et autres personnages historiques. C'est dire à quel point les discours sur l'identité supposée du pays et des Français, servis à longueur de tribunes et de plateaux, ne sont pas seulement pauvres, ils sont aussi assassins (voir les contributions de Robert Maggiori et de Yves Charles Zarka).

L'identité n'est pas l'identique. Influencée par les travaux de Ricœur, Zarka renvoie, dans l'introduction générale, la définition de l'identité au « rapport de soi à soi, [au] travail de soi sur soimême ». D'où l'importance non pas du récit mais des récits, qui laissent entendre d'autres voix et dissonances. Mais attention, ces récits ne condamnent pas un pays à l'éclatement: ces contradictions et désaccords, ces priorités, le jeu des " écarts », pour reprendre le concept forgé par François Jullien, sont aussi ce qui fonde le commun d'une histoire, le commun d'un peuple et d'une nation. Jusque dans la part indispensable de mythes et de fictions. D'où la place que tiennent les arts et les lettres. Si "l'intimité d'un peuple c'est sa littérature » (Amin Maalouf, Les dérèglements du monde, Grasset, 2009), il est bon de voir les écrivains contemporains mettre en récits la France moderne, à la fois ancienne et neuve.

Le livre est organisé en quatre entrées: "Sensibilité, goût, esprit » ; " La langue française ici et ailleurs »; " La guerre des mémoires »; et enfin « La société, les institutions et l'État ». Les entrées commencent avec NotreDame de Paris, les prix littéraires, le cinéma, le vin ou la place des intellectuels. Elles se poursuivent avec la francophonie la querelle des origines, la place de la Révolution française, le Vel' d'Hiv', la guerre d'Algérie ou les récits religieux. Elles se referment sur la laïcité (Henri Peña-Ruiz), les droits de l'Homme (Otto Pfersmann) ou le « détricotage du modèle social » (Michel Margairaz)... Un magnifique et instructif voyage, rarement ennuyeux tout du long. Certes, l'unité de la France et de ce que Yves Charles Zarka appelle l'identité " ne ressemble pas à un long fleuve tranquille ». Mais l'eau et le mouvement ne constituent-ils pas les indispensables à et de la vie? M. $\mathrm{H}$, 